\title{
Patient factors associated with new prescribing of potentially inappropriate medications in multimorbid US older adults using multiple medications
}

\author{
Katharina Tabea Jungo $0^{1,2,3,4^{*}}$ (D) Sven Streit ${ }^{1}$ (D) and Julie C. Lauffenburger ${ }^{3,5}$ (D)
}

\begin{abstract}
Background: The use of potentially inappropriate medications (PIMs) is common in older adults and is associated with potential negative consequences, such as falls and cognitive decline. Our objective was to investigate measurable patient factors associated with new outpatient prescribing of potentially inappropriate medications in older multimorbid adults already using multiple medications.

Methods: In this retrospective US cohort study, we used linked Medicare pharmacy and medical claims and electronic health record data from a large healthcare system in Massachusetts between 2007 and 2014. We identified patients aged $\geq 65$ years with an office visit who had not been prescribed or used a PIM in the prior 180 days. PIMs were defined using 2019 Beers criteria of the American Geriatrics Society. To specifically evaluate factors in patients with polypharmacy and multimorbidity, we selected those who filled medications for $\geq 90$ days (i.e., chronic use) from $\geq 5$ pharmaceutical classes in the prior 180 days and had $\geq 2$ chronic conditions. Multivariable Cox regression analysis was used to estimate the association between baseline demographic and clinical characteristics on the probability of being prescribed a PIM in the 90-day follow-up period.

Results: In total, we identified 17,912 patients aged $\geq 65$ years with multimorbidity and polypharmacy who were naïve to a PIM in the prior 180 days. Of those, 10,497 (58.6\%) were female, and mean age was 78 (SD = 7.5). On average, patients had $5.1(\mathrm{SD}=2.3)$ chronic conditions and previously filled $6.1(\mathrm{SD}=1.4)$ chronic medications. In total, 447 patients (2.5\%) were prescribed a PIM during the 90-day follow-up. Male sex (adjusted hazard ratio $(H R)=$ 1.29; 95\%Cl: 1.06-1.57), age ( $\geq 85$ years: $H R=0.75,95 \% C l: 0.56-0.99,75-84$ years: $H R=0.87,95 \% C l: 0.71-1.07$; reference: $65-74$ years), ambulatory visits (18-29 visits: $\mathrm{HR}=1.42,95 \% \mathrm{Cl}: 1.06-1.92 ; \geq 30$ visits: $\mathrm{HR}=2.12,95 \% \mathrm{Cl}: 1.53-$ 2.95; reference: $\leq 9$ visits), number of prescribing orders ( $H R=1.02,95 \% \mathrm{Cl}: 1.01-1.02$ per 1-unit increase), and heart failure ( $\mathrm{HR}=1.38,95 \% \mathrm{Cl}: 1.07-1.78)$ were independently associated with being newly prescribed a PIM.

(Continued on next page)
\end{abstract}

\footnotetext{
* Correspondence: katharina.jungo@protonmail.com

IInstitute of Primary Health Care (BIHAM), University of Bern, Bern,

Switzerland

2Department of Epidemiology, Harvard T.H. Chan School of Public Health, Boston, MA, USA

Full list of author information is available at the end of the article
}

(c) The Author(s). 2021 Open Access This article is licensed under a Creative Commons Attribution 4.0 International License, which permits use, sharing, adaptation, distribution and reproduction in any medium or format, as long as you give appropriate credit to the original author(s) and the source, provide a link to the Creative Commons licence, and indicate if changes were made. The images or other third party material in this article are included in the article's Creative Commons licence, unless indicated otherwise in a credit line to the material. If material is not included in the article's Creative Commons licence and your intended use is not permitted by statutory regulation or exceeds the permitted use, you will need to obtain permission directly from the copyright holder. To view a copy of this licence, visit http://creativecommons.org/licenses/by/4.0/ The Creative Commons Public Domain Dedication waiver (http://creativecommons.org/publicdomain/zero/1.0/) applies to the data made available in this article, unless otherwise stated in a credit line to the data. 
(Continued from previous page)

Conclusion: Several demographic and clinical characteristics, including factors suggesting lack of care coordination and increased clinical complexity, were found to be associated with the new prescribing of potentially inappropriate medications. This knowledge could inform the design of interventions and policies to optimize pharmacotherapy for these patients.

Keywords: Multimorbidity, Polypharmacy, Potentially inappropriate prescribing

\section{Introduction}

The prevalence of older adults is growing in the United States and many countries globally, in large part because of increasing life expectancy [1]. At the same time, the prevalence of multimorbidity, commonly defined as having $\geq 2$ chronic conditions [2], is also on the rise [3]. Accordingly, due to the association between multimorbidity and age [4], multimorbidity is becoming increasingly common in older adults. Multimorbidity poses one of the greatest challenges to health systems, because multimorbid patients often have complex healthcare needs and worse health outcomes [5, 6], including higher rates of mortality, disability, lower quality of life, and adverse drug events $[7,8]$. Another challenge associated with multimorbidity is the increasing number of medications that patients need to take to manage their conditions.

Multimorbid patients often have polypharmacy, i.e., the concurrent use of $\geq 5$ medications [9]. For instance, $39 \%$ of community-dwelling US older adults have polypharmacy [10]. Polypharmacy increases the risk of using potentially inappropriate medications (PIMs) [8-10]. PIMs are drugs for which the risk of potential adverse events is greater than the clinical benefits, particularly when there are safer or more effective alternatives that are recommended to be used in older adults [11]. In specific, PIMs are associated with increased risk of adverse drug events, falls, and cognitive impairment [12-15] as well as greater use of healthcare services (e.g., hospitalizations or emergency department visits) and healthcare costs [16-19].

Contributors to the prescribing of PIMs are multifaceted [20]. For example, provider and health-system factors leading to prescribing of PIMs are thought to include lack of communication between different prescribers, providers' lack of knowledge in geriatric medicine and pharmacology, and insufficient time allocated to prescribing. Previous research on patient factors associated with the prescribing of potentially inappropriate medications for older adults have focused on broad populations of community-dwelling older adults or patients with selected chronic conditions [21-23]. Unfortunately, even though PIM use is high among multimorbid older adults using multiple medications, little is known about the patient factors associated with the new prescribing of potentially inappropriate medications in this population group, despite it being at even greater risk of adverse health outcomes than general older adults.

Therefore, the aim of this study was to explore the factors associated with new prescribing of potentially inappropriate medications in older multimorbid men and women with polypharmacy in the US. Investigating these factors could inform the design of interventions and policies aimed at optimizing pharmacotherapy in this patient group.

\section{Methods \\ Data source}

In this retrospective study, we used a dataset containing Medicare claims linked with electronic health records (EHR) of patients enrolled in the Partners Research Patient Data Registry (RPDR) [24]. The Partners Research Patient Data Registry contains EHR data from two tertiary medical centers, three community hospitals, a Rehabilitation center, and a psychiatric hospital that are located in the Boston metropolitan area. The dataset contains data from 569,969 participants from January 1, 2007 through December 31, 2014. Medicare claims include Parts A (inpatient coverage), B (outpatient coverage), and D (drug coverage) containing information on drugs dispensed and start/end dates of insurance coverage $[25,26]$. The EHR data contain information on sociodemographic variables, health services use (e.g., ambulatory visits and inpatient care), prescribing records, laboratory tests, and results.

\section{Patient population}

This research uses the same approach to define polypharmacy and multimorbidity as our previous research on the use of potentially inappropriate medications in older multimorbid adults with polypharmacy [27]. The key features of this approach are outlined below.

\section{Definition of multimorbidity}

We defined the chronic conditions using the Chronic Condition Indicator (CCI) of the Agency for Healthcare Research and Quality (AHRQ). The CCI categorizes ICD-9 diagnosis codes as chronic and not chronic [28]. After extracting the chronic ICD-9 codes, we assigned related codes to ICD-9 code categories. This ensured 
that we did not misclassify patients with closely-related diagnoses codes (e.g. different types of cancers) as having multiple chronic conditions. Chronic conditions from the CCI related to pregnancy and childbirth were excluded due to their non-relevance in our study population. In total, there were 77 chronic condition categories. To increase the specificity of underlying chronic conditions, $\geq 2$ diagnosis codes on separate days were required for the condition to count as a chronic condition [29]. Because a definition of two or more chronic diseases is commonly used in the literature to define multimorbidity $[2,30,31]$, we used this threshold to define patients as multimorbid.

\section{Definition of polypharmacy}

We used information from the U.S. Food and Drug Administration (FDA) on the classification of medications into different pharmaceutical classes (e.g., anticholinergics) [32] to define polypharmacy. We measured medication use at the class level, as medications with structural similarities, such as statins, are generally considered interchangeable. Medication classes with $\geq 90$ days' supply were considered as being used chronically [33]. We measured days' supply from claims conservatively to ascertain long-term polypharmacy. First, we assumed concurrent utilization if there were multiple fills for the same class on the same day, and if the recorded days' supply differed, the medication with the longest duration was selected. Next, a limited shift of supply (30 days) was used for overlapping utilization in the case of nonconcurrent fills. We defined patients as having polypharmacy when they filled medications from $\geq 5$ pharmaceutical classes with $\geq 90$ days' supply each, in line with commonly used definitions for polypharmacy and previously used approaches for measuring chronic use $[9,34,35]$.

\section{Cohort definition}

The cohort was created using the Aetion Evidence Platform (Version: r3.5.20180426_1659), which has previously been validated for a range of studies $[25,36]$. An ambulatory visit recorded in the RPDR electronic health records constituted the cohort entry event. From that index ambulatory visit, we excluded patients if they were $<65$ years of age, if there was missing information on sex, or if they did not have 180 days Medicare (part $\mathrm{D}$, drug coverage) enrolment prior to the cohort entry to ensure complete data capture. As a result, the effective cohort entry date of patients in our cohort was July 1 , 2007 at the earliest. If a patient had multiple possible qualifying ambulatory visits, the patient entered the cohort on the first-occurring qualifying event after exclusions (age, missing sex, and Medicare enrolment) were applied. Patients were only counted once and could not re-enter the cohort at a later stage. Then, we excluded patients who were prescribed or used potentially inappropriate medications during the baseline period, to focus on new PIM prescribing. Next, to ascertain continuity of care and to reduce information bias, we excluded patients who did not have an ambulatory visit during the baseline period of 180 days and for whom there thus was no "data continuity" [37]. Finally, we selected patients with $\geq 2$ chronic conditions and $\geq 5$ medication classes with long-term use (i.e., $\geq 90$ days' supply each), as they were the population of interest. A cohort flow diagram can be found in Fig. 1.

\section{Outcome measurement}

\section{Prescribing of potentially inappropriate medications}

The identification of potentially inappropriate medications can be done using different implicit (judgmentbased) or explicit (criterion-based) lists. The Beers list, published by the American Geriatrics Society (AGS) [38-40], is one example of a criterion-based list. We decided to use the 2019 Beers list, rather than previous versions, to identify potentially inappropriate medications with the aim of informing current medical decision-making [39]. We defined all medications prescribed in the EHR that met any of the drug, duration and dosage requirements described in Table 2 of the 2019 Beers criteria as potentially inappropriate. Certain medications on the Beers list are considered potentially inappropriate only when they are used in presence or absence of a certain diagnosis, when a lab value is below/above a certain value, or when they are used for more than a certain number of days (refer to eTable 1 in the Supplement for details). Using this linked claims and EHR dataset, we were able to capture all the clinical criteria necessary to define PIMs (e.g., diagnoses, lab results).

We measured whether patients in our cohort were newly-prescribed a potentially inappropriate medication in the outpatient setting during a 90-day follow-up period, including the index ambulatory visit (any). For reasons related to continuity of care, we limited our analyses to this 90-day follow-up period. Furthermore, this follow-up period seemed reasonable in our study population with a relatively high health services use (i.e., median number of ambulatory visits during the 180-day baseline period $=17$ ).

\section{Covariates}

We used peer-reviewed literature to identify patient factors hypothesized to be associated with the prescribing of potentially inappropriate medications and that could also be measured in our EHR-claims dataset [41, 42]. These factors were measured in the 180 days before the index ambulatory visit. The following covariates were included 


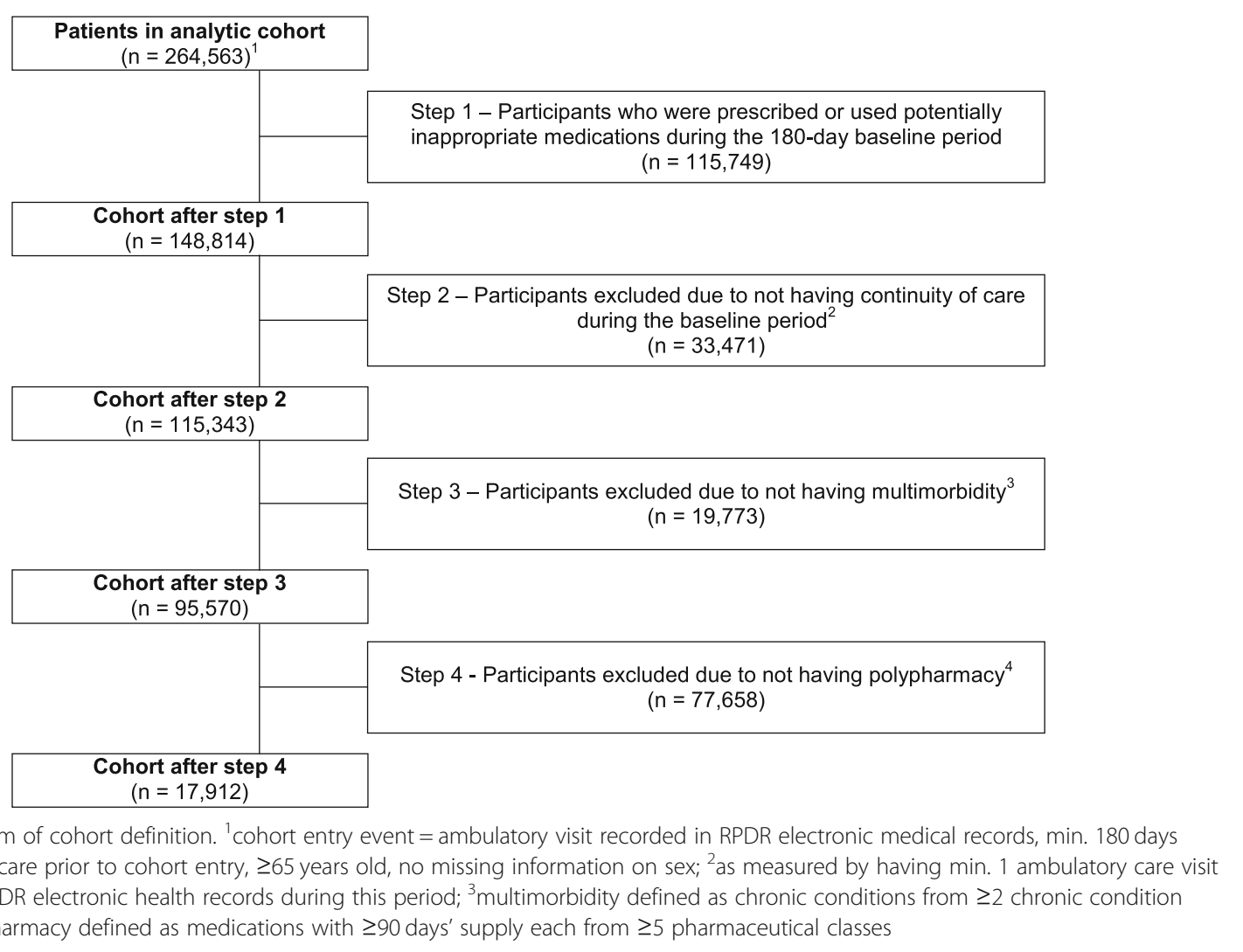

in our models: age, sex, ethnicity, race, number of inpatient stays, emergency department visits, ambulatory visits, non-acute institutional stays, level of polypharmacy (5-9 medications vs $\geq 10$ ), number of chronic conditions, number of prescribing orders, and selected chronic conditions defined by Elixhauser Comorbidities [43] (shown in Table 2). Sensitivity analyses involved measuring a claims-based frailty index [44].

\section{Statistical analyses}

The sociodemographic and clinical characteristics of patients were described for those who were and were not prescribed a potentially inappropriate medication during the 90-day follow-up. To facilitate interpretation, some continuous variables were categorized based on quartiles for ambulatory visits and percentiles for inpatient stays, emergency department visits, and non-acute stays. We provided absolute standardized differences, which are the differences in the mean of a covariate between two groups, to show any differences between groups [45].

Cox regression analysis was conducted to estimate the effect of baseline demographic and clinical characteristics on the probability of being prescribed a new PIM during the 90-day follow-up period. We chose Cox regression analysis in particular as the primary analysis to better model the likelihood of prescribing as a function of time. In specific, we computed hazard ratios (HR) and 95\% confidence intervals (CI). First, we tested each variable separately, without adjusting for other covariates, using Cox proportional hazards regression analysis to estimate its association with the new prescribing of potentially inappropriate medications. Next, we used multivariable Cox proportional hazards regression analysis to examine the association between each variable and the prescribing of PIMs, while adjusting for other covariates. In the first multivariable model, we included demographic and healthcare utilization variables. In the second one, we added information on the types of chronic conditions. The first encounter in which a PIM was prescribed was analyzed in the time-to-event analyses. Finally, we analyzed the types of PIMs prescribed in the follow-up period.

We also performed some subgroup (e.g., restricted to patients with $\geq 1$ prescribing order in the baseline period, with $\geq 2$ ambulatory visits in the baseline period) and sensitivity analyses (e.g., exclude Beers criteria with a low level of evidence, adding a claims-based frailty index to the model, extending the baseline period to 365 days, and keeping all continuous variables in their original form). In addition, we performed a multivariable logistic regression with the same outcome and same variables in the model. We performed all analyses using STATA 
15.1 (StataCorp, College Station, TX, USA). Statistical significance was determined by using two-sided tests with an $\alpha$ of 0.05 .

This study was approved by the Brigham and Women's Hospital Institutional Review Board. We followed the reporting requirements of the 'Strengthening the Reporting of Observational Studies in Epidemiology' (STROBE) guidelines [46].

\section{Results}

In total, we identified 17,912 older adults with multimorbidity and polypharmacy who were naive to a potentially inappropriate medication in the prior 180 days and met all other inclusion and exclusion criteria (Fig. 1). Of these, $447(2.5 \%)$ were prescribed a new potentially inappropriate medication during the 90-day follow-up period. Central nervous system drugs, cardiovascular drugs, anticholinergics, and endocrine drugs were the most commonly prescribed PIMs (Table 1 ). Benzodiazepines were prescribed in $29 \%$ of patients who were newly prescribed a central nervous system PIM.

Table 2 shows the baseline characteristics of all patients overall and by whether they were newlyprescribed a PIM. In the entire cohort, the average age was 78 years $(\mathrm{SD}=7.5)$, and $58.6 \%$ of patients were female. Patients newly-prescribed a PIM differed from those who were not prescribed a PIM; for example, new PIM prescribing was higher among men and those with greater prior healthcare services use. The types of chronic conditions were relatively comparable between the two groups at baseline, except for congestive heart failure.

Unadjusted and multivariable Cox regression of the association between measured patient factors and the risk of being prescribed a PIM in older multimorbid patients with polypharmacy are shown in Table 3 . Of note, there were no violations of the proportional hazards' assumption. In unadjusted analyses, increased age (i.e. $\geq 85$ years), male sex, and some racial groups (e.g. Black) were associated with being newly-prescribed a potentially inappropriate medication (Table 3). Most variables measuring the health services use of patients, such as the number of inpatient stays, number of emergency department visits, number of ambulatory visits, and the number of prescribing orders were associated with an increased risk of PIM prescribing. The number of chronic conditions and some types of chronic conditions (i.e. congestive heart failure, cardiac arrhythmias) were also associated with new PIM prescriptions.

In the multivariable analysis including demographic and healthcare utilization variables, male sex, Black race, $\geq 85$ years of age, number of ambulatory visits ( $\geq 18$ visits during the baseline period), and number of prescribing orders were associated with new PIM prescribing. In
Table 1 Potentially inappropriate medications (PIMs) prescribed during the 90-day follow-up period $(N=17,912)$

\begin{tabular}{|c|c|}
\hline \multirow[t]{2}{*}{$\begin{array}{l}\text { Types of potentially inappropriate } \\
\text { medications }\end{array}$} & \multirow{2}{*}{$\begin{array}{l}\text { Potentially inappropriate } \\
\text { medications } \\
\text { Number of patients } \\
\text { (\% of total number of } \\
\text { patients with PIM prescription) }\end{array}$} \\
\hline & \\
\hline All & 447 (2.5\% of patients in cohort) \\
\hline Anticholinergics & $64(14.3)$ \\
\hline First-generation antihistamines & $52(11.6)$ \\
\hline Antiparkinsonian agents & $* *$ \\
\hline Antispasmodics & ** \\
\hline Anti-infective (Nitrofurantoin) & $* *$ \\
\hline Cardiovascular & $90(20.1)$ \\
\hline Peripheral alpha-1 blockers & $14(3.1)$ \\
\hline Central alpha agonists & $* *$ \\
\hline Disopyramide & $* *$ \\
\hline Digoxin & $57(12.8)$ \\
\hline Nifedipine & $* *$ \\
\hline Amiodarone & $21(4.7)$ \\
\hline Central nervous system & $185(41.4)$ \\
\hline Antidepressants & $* *$ \\
\hline Antipsychotics & $35(7.8)$ \\
\hline Barbiturates & $* *$ \\
\hline Benzodiazepines & $130(29.1)$ \\
\hline Nonbenzodiazepine & $29(6.5)$ \\
\hline Endocrine & $77(17.2)$ \\
\hline Androgens & $* *$ \\
\hline Growth hormone & $16(3.6)$ \\
\hline Insulin & $39(8.7)$ \\
\hline Megestrol & ** \\
\hline Sulfonylureas & $16(3.6)$ \\
\hline Gastrointestinal & $20(4.5)$ \\
\hline Metoclopramide & $12(2.7)$ \\
\hline Mineral oil & $* *$ \\
\hline Proton-pump inhibitors & $* *$ \\
\hline Pain medications & $54(12.1)$ \\
\hline $\begin{array}{l}\text { Non-cycloocygenase-selective NSAI } \\
\text { Ds }\end{array}$ & $17(3.8)$ \\
\hline Indomethacin, ketorolac & $20(4.5)$ \\
\hline Skeletal muscle relaxants & $18(4.0)$ \\
\hline
\end{tabular}

** cells $<11$ suppressed for data protection reasons according to Medicare requirements

Not presented due to not having been prescribed during the 90-day follow-up period: Antithrombotics (Dipyridamole), Dronedrone, Meprobamate, Ergoloid mesylates, Desiccated thyroid Estrogens, Meperidine,

Genitourinary (Desmopressin)

model 2, including chronic conditions, we observed similar results. In this model, male sex (adjusted hazard ratio $(\mathrm{HR})=1.29 ; 95 \% \mathrm{CI}: 1.06-1.57)$, age $(\geq 85$ years: 
Table 2 Baseline characteristics, by whether the participants had a new prescription of a potentially inappropriate medication (PIM) during the 90-day follow-up period

\begin{tabular}{|c|c|c|c|c|}
\hline & All patients & $\begin{array}{l}\text { Patients with new } \\
\text { PIM prescription } \\
\text { during follow-up }\end{array}$ & $\begin{array}{l}\text { Patients without new } \\
\text { PIM prescription during } \\
\text { follow-up }\end{array}$ & $\begin{array}{l}\text { Absolute } \\
\text { standardized } \\
\text { differences }^{d}\end{array}$ \\
\hline & $(n=17,912)$ & $(n=447)$ & $(N=17,465)$ & \\
\hline \multicolumn{5}{|l|}{ Demographic characteristics } \\
\hline Mean age in years (SD) & $78.0(7.5)$ & $77.0(7.5)$ & $78.0(7.5)$ & 0.13 \\
\hline Female sex (\%) & $10,497(58.6)$ & $225(50.3)$ & $10,272(58.8)$ & 0.17 \\
\hline Hispanic ethnicity (\%) & $161(0.9)$ & $* *$ & $* *$ & 0.04 \\
\hline \multicolumn{5}{|l|}{ Race (\%) } \\
\hline White & $16,593(92.6)$ & $398(89.0)$ & $16,195(92.7)$ & 0.13 \\
\hline Black & $653(3.7)$ & $24(5.4)$ & $629(3.6)$ & \\
\hline Asian & $165(0.9)$ & $* *$ & $* *$ & \\
\hline Other & $417(2.3)$ & $17(3.8)$ & $400(2.3)$ & \\
\hline No information & $84(0.5)$ & $* *$ & $* *$ & \\
\hline \multicolumn{5}{|l|}{ Medication intake } \\
\hline $\begin{array}{l}\text { Mean (SD) drug items dispensed per patient with } \\
\text { min. } 90 \text { days' supply }\end{array}$ & $6.1(1.4)$ & $6.2(1.4)$ & $6.1(1.4)$ & 0.07 \\
\hline Mean (SD) drug items dispensed & $8.0(2.4)$ & $8.2(2.5)$ & $8.0(2.4)$ & 0.08 \\
\hline \multicolumn{5}{|l|}{ Healthcare utilization } \\
\hline Patients with at least 1 inpatient stay (\%) & $3001(16.7)$ & $97(21.7)$ & $2904(16.6)$ & 0.13 \\
\hline Patients with at least 1 emergency department visit (\%) & $4711(26.3)$ & $143(32.0)$ & $4568(26.2)$ & 0.13 \\
\hline Patients with at least 1 non-acute institutional stay (\%) & $2360(13.2)$ & $45(10.1)$ & $2315(13.3)$ & 0.10 \\
\hline $\begin{array}{l}\text { Patients with number of ambulatory visits above the } \\
\text { median number of ambulatory visits (median }=17)(\%)^{\mathrm{b}}\end{array}$ & $9186(51.3)$ & $293(65.6)$ & $8893(50.9)$ & 0.30 \\
\hline \multicolumn{5}{|l|}{ Number of chronic conditions } \\
\hline Mean (SD) number of chronic conditions & $5.1(2.3)$ & $5.4(2.5)$ & $5.1(2.3)$ & 0.12 \\
\hline \multicolumn{5}{|l|}{ Chronic conditions types ${ }^{a}(\%)$} \\
\hline Congestive heart failure & $2931(16.4)$ & $103(23.0)$ & $2828(16.2)$ & 0.17 \\
\hline Cardiac arrhythmias & $1061(5.9)$ & $37(8.3)$ & $1024(5.9)$ & 0.10 \\
\hline Valvular disease & $2109(11.8)$ & $56(12.5)$ & $2053(11.8)$ & 0.02 \\
\hline Pulmonary circulation disorders & $399(2.2)$ & $83(18.6)$ & $2748(15.7)$ & 0.08 \\
\hline Peripheral vascular disorders & $2525(14.1)$ & $70(16.7)$ & $2455(14.1)$ & 0.05 \\
\hline Hypertension & $11,309(63.1)$ & $285(63.8)$ & $11,024(63.1)$ & 0.01 \\
\hline Chronic pulmonary disorders & $2831(15.8)$ & $83(18.6)$ & $2748(15.7)$ & 0.08 \\
\hline Diabetes & $5718(31.9)$ & $161(36.0)$ & $5557(31.8)$ & 0.09 \\
\hline Hypothyroidism & $2531(14.1)$ & $59(13.2)$ & $2472(14.2)$ & 0.03 \\
\hline Renal failure & $1669(9.3)$ & $46(10.3)$ & $1623(9.3)$ & 0.03 \\
\hline Liver disease & $274(1.5)$ & $* *$ & $* *$ & 0.08 \\
\hline Cancer & $2447(13.7)$ & $67(15.0)$ & $2380(13.6)$ & 0.04 \\
\hline Rheumatoid arthritis / collagen vascular diseases & $940(5.3)$ & $20(4.5)$ & $920(5.3)$ & 0.04 \\
\hline Coagulopathy & $619(3.5)$ & $19(4.3)$ & $600(3.4)$ & 0.04 \\
\hline Fluid and electrolyte disorders & $783(4.4)$ & $25(5.6)$ & $758(4.3)$ & 0.06 \\
\hline Psychoses & $309(1.7)$ & ** & $* *$ & 0.05 \\
\hline Depression & $1580(8.8)$ & $38(8.5)$ & $1542(8.8)$ & 0.01 \\
\hline
\end{tabular}


Table 2 Baseline characteristics, by whether the participants had a new prescription of a potentially inappropriate medication (PIM) during the 90-day follow-up period (Continued)

\begin{tabular}{|c|c|c|c|c|}
\hline & All patients & $\begin{array}{l}\text { Patients with new } \\
\text { PIM prescription } \\
\text { during follow-up }\end{array}$ & $\begin{array}{l}\text { Patients without new } \\
\text { PIM prescription during } \\
\text { follow-up }\end{array}$ & $\begin{array}{l}\text { Absolute } \\
\text { standardized }^{\text {differences }}{ }^{d}\end{array}$ \\
\hline & $(n=17,912)$ & $(n=447)$ & $(N=17,465)$ & \\
\hline \multicolumn{5}{|l|}{ Other characteristics } \\
\hline Mean frailty index $(S D)^{c}$ & $0.16(0.1)$ & $0.16(0.1)$ & $0.16(0.1)$ & 0.04 \\
\hline \multicolumn{5}{|c|}{ 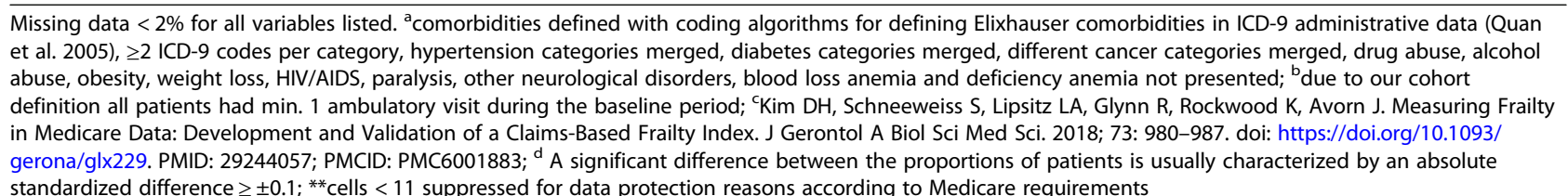 } \\
\hline
\end{tabular}

$\mathrm{HR}=0.75,95 \% \mathrm{CI}: 0.56-0.99,75-84$ years: $\mathrm{HR}=0.87$, 95\%CI: $0.71-1.07$; reference: $65-74$ years), number of ambulatory visits $(18-29$ visits: $\mathrm{HR}=1.42$, 95\%CI: $1.06-$ 1.92 ; $\geq 30$ visits: $\mathrm{HR}=2.12,95 \% \mathrm{CI}: 1.53-2.95$, reference: $\leq 9$ visits), the number of prescribing orders $(\mathrm{HR}=$ 1.02 per 1 -unit increase, $95 \% \mathrm{CI}$ : 1.01-1.02), and a heart failure diagnosis $(\mathrm{HR}=1.38,95 \% \mathrm{CI}$ : $1.07-1.78)$ were associated with being newly-prescribed a PIM, but Black race was no longer significantly associated with new PIM prescribing.

Extending the baseline period to 365 days (eTable 2) and analyzing all continuous variables as continuous variables (eTable 3) did not change the results, and there were similar results using multivariable logistic regression (eTable 4). Similar results were also observed when restricting the analyses to Beers criteria with moderate or high level of evidence (eTable 5). When analyzing patients with $\geq 3$ chronic conditions (eTable 6) or those with $\geq 2$ ambulatory visits during the baseline period (eTable 7 ), we found however that age ( $\geq 85$ years) and Black race where no longer significantly associated with new PIM prescribing. Age was also no longer significantly associated when adding a claims-based frailty index to the model (eTable 8).

\section{Discussion}

This is the first study exploring factors associated with new prescribing of potentially inappropriate medications in older multimorbid adults with polypharmacy in a US sample without prior PIM use. Of the $2.5 \%$ of patients who were newly prescribed a PIM within the follow-up period of 90 days, male sex, more ambulatory visits, more prescriptions, and prior diagnosis of heart failure were associated with new receipt of a PIM prescription and being $\geq 85$ years of age was associated with a lower risk of new PIM prescribing. Central nervous system drugs, cardiovascular drugs, anticholinergics, and endocrine drugs were the most commonly prescribed PIMs. The finding that benzodiazepines was the most commonly prescribed PIM is in line with previous research [21, 47].

Of the patient demographic factors found to be associated with new PIM prescribing, male sex, and Black race were found to be associated with an increased risk of a new prescription for a PIM, while advanced age was found to be associated with an decrease risk of a new PIM prescription. Prior literature is inconclusive on whether sex is associated with the prescribing of PIMs. While some studies found an association with female sex and PIM prescribing $[22,48]$, others did not find any significant association $[21,49,50]$. Most previous studies were cross-sectional, which does not provide evidence about the incidence of new PIM prescribing and factors associated with it.

Our results were mixed on whether there is an association between the new prescribing of PIMs and age. In our main model, we observed that those $\geq 85$ years had a lower risk of new PIM prescribing, but this was no longer significant in some sensitivity analyses. Similarly, while some previous studies did not observe any association, others also found a protective factor of age [48, 51]. Furthermore, when examining Black race we found mixed results, as Black race was no longer significantly associated with PIM prescribing after adjusting for the types of chronic conditions. Prior research in more general populations of older adults has, in fact, found a positive association between white race and greater PIM prescribing $[52,53]$.

We found that an above median number of ambulatory care visits and the number of prescribing orders were positively associated with PIM prescribing, which could be indicators of clinical complexity. Current literature on PIM prescribing and health services use is mixed: one study found an association between inpatient stays, emergency department visits and outpatient visits [54], while another one did not find an association between PIM prescribing and outpatient visits [50]. There is some evidence that PIM prescribing may be positively associated with the number of prescribers [21]. 
Table 3 Unadjusted and multivariable associations between demographic and clinical factors and the prescribing of potentially inappropriate medications during the 90-day follow-up period

\begin{tabular}{|c|c|c|c|c|c|c|}
\hline \multirow[t]{3}{*}{$\begin{array}{l}\text { Demographics and clinical } \\
\text { characteristics }\end{array}$} & \multicolumn{2}{|c|}{ Unadjusted associations } & \multicolumn{2}{|c|}{$\begin{array}{l}\text { Model 1: Demographic and } \\
\text { healthcare utilization variables }\end{array}$} & \multicolumn{2}{|c|}{$\begin{array}{l}\text { Model 2: Model } 1+\text { chronic } \\
\text { conditions }\end{array}$} \\
\hline & $\begin{array}{l}\text { Unadjusted hazard } \\
\text { ratio }\end{array}$ & $95 \% \mathrm{Cl}$ & $\begin{array}{l}\text { Adjusted hazard } \\
\text { ratio }\end{array}$ & $95 \% \mathrm{Cl}$ & $\begin{array}{l}\text { Adjusted hazard } \\
\text { ratio }\end{array}$ & $95 \% \mathrm{Cl}$ \\
\hline & $(N=17,912)$ & & $(n=17,911)$ & & $(n=17,911)$ & \\
\hline \multicolumn{7}{|l|}{ Age (reference: 65-74) } \\
\hline $75-84$ & 0.85 & $0.69-1.04$ & 0.86 & $0.70-1.06$ & 0.87 & $0.71-1.07$ \\
\hline 85 and above & 0.67 & $0.52-0.88^{* *}$ & 0.76 & $0.58-0.99^{* *}$ & 0.75 & $0.56-0.99^{* *}$ \\
\hline Male sex (reference: female sex) & 1.41 & $1.17-1.79 * * *$ & 1.30 & $1.08-1.57^{* *}$ & 1.29 & $1.06-1.57^{* *}$ \\
\hline Hispanic ethnicity (reference: non-hispanic) & 1.51 & $0.67-3.38$ & 0.96 & $0.35-2.59$ & 0.95 & $0.35-2.67$ \\
\hline \multicolumn{7}{|l|}{ Race (reference: White) } \\
\hline Asian & 1.26 & $0.52-3.03$ & 1.37 & $0.57-3.31$ & 1.31 & $0.54-3.17$ \\
\hline Black & 1.54 & $1.02-2.33^{* *}$ & 1.54 & $1.02-2.33^{* *}$ & 1.50 & $0.98-2.27$ \\
\hline Other & 1.71 & $1.05-1.78^{* *}$ & 1.64 & $0.90-2.99$ & 1.59 & $0.87-2.90$ \\
\hline \multicolumn{7}{|l|}{ Number of inpatient stays (reference: $0^{b}$ ) } \\
\hline At least 1 & 1.39 & $1.11-1.75^{* *}$ & 0.98 & $0.72-1.33$ & 0.94 & $0.69-1.28$ \\
\hline \multicolumn{7}{|l|}{$\begin{array}{l}\text { Number of emergency department visits } \\
\text { (reference: } 0^{c} \text { ) }\end{array}$} \\
\hline At least 1 & 1.33 & $1.09-1.62^{* *}$ & 1.12 & $0.86-1.33$ & 1.09 & $0.84-1.41$ \\
\hline \multicolumn{7}{|l|}{ Number of ambulatory visits (reference: $\leq 9^{d}$ ) } \\
\hline $10-17$ & 0.94 & $0.70-1.28$ & 0.96 & $0.70-1.31$ & 0.96 & $0.70-1.31$ \\
\hline $18-29$ & 1.39 & $1.05-1.84^{* *}$ & 1.42 & $1.05-1.91^{* *}$ & 1.42 & $1.06-1.92^{* *}$ \\
\hline$\geq 30$ & 2.12 & $1.64-2.76^{* * *}$ & 2.12 & $1.55-2.93^{* *}$ & 2.12 & $1.53-2.95^{* *}$ \\
\hline \multicolumn{7}{|l|}{$\begin{array}{l}\text { Number of non-acute institutional stays } \\
\text { (reference: } 0^{e} \text { ) }\end{array}$} \\
\hline At least 1 & 0.74 & $0.55-1.01$ & 0.81 & $0.58-1.13$ & 0.76 & $0.54-1.08$ \\
\hline \multicolumn{7}{|l|}{$\begin{array}{l}\text { Level of polypharmacy } \\
\text { (reference: 5-9 medications) }\end{array}$} \\
\hline 10 and above & 1.27 & $0.77-2.09$ & 1.16 & $0.70-1.92$ & 1.08 & $0.65-1.79$ \\
\hline $\begin{array}{l}\text { Number of chronic conditions } \\
\text { (1-unit increase) }\end{array}$ & 1.06 & $1.02-1.10^{* *}$ & 0.96 & $0.91-1.01$ & 0.94 & $0.88-1.01$ \\
\hline $\begin{array}{l}\text { Number of prescribing orders } \\
\text { (1-unit increase) }\end{array}$ & 1.02 & $1.01-1.02^{* * *}$ & 1.02 & $1.01-1.02^{* * *}$ & 1.02 & $1.01-1.02^{* * *}$ \\
\hline \multicolumn{7}{|l|}{ Types of chronic conditions ${ }^{a}$} \\
\hline Congestive heart failure & 1.56 & $1.25-1.94^{* * *}$ & - & - & 1.38 & $1.07-1.78^{* *}$ \\
\hline Cardiac arrhythmias & 1.44 & $1.03-2.02^{* *}$ & - & - & 1.02 & $0.71-1.46$ \\
\hline Valvular disease & 1.08 & $0.82-1.43$ & - & - & 0.85 & $0.63-1.15$ \\
\hline Pulmonary circulation disorders & 1.64 & $0.99-2.71$ & - & - & 1.41 & $0.84-2.38$ \\
\hline Peripheral vascular disorders & 1.14 & $0.88-1.47$ & - & - & 1.09 & $0.84-1.42$ \\
\hline Hypertension & 1.03 & $0.85-1.25$ & - & - & 0.98 & $0.78-1.22$ \\
\hline Chronic pulmonary disorders & 1.23 & $0.97-1.56$ & - & - & 1.10 & $0.85-1.43$ \\
\hline Diabetes & 1.20 & $0.99-1.46$ & - & - & 1.15 & $0.93-1.43$ \\
\hline Hypothyroidism & 0.92 & $0.70-1.21$ & - & - & 1.08 & $0.81-1.45$ \\
\hline Renal failure & 1.13 & $0.83-1.53$ & - & - & 0.90 & $0.65-1.25$ \\
\hline Cancer & 1.12 & $0.86-1.45$ & - & - & 0.88 & $0.66-1.17$ \\
\hline Rheumatoid arthritis/collagen & 0.85 & $0.54-1.33$ & - & - & 0.81 & $0.51-1.28$ \\
\hline
\end{tabular}


Table 3 Unadjusted and multivariable associations between demographic and clinical factors and the prescribing of potentially inappropriate medications during the 90-day follow-up period (Continued)

\begin{tabular}{|c|c|c|c|c|c|c|}
\hline \multirow[t]{3}{*}{$\begin{array}{l}\text { Demographics and clinical } \\
\text { characteristics }\end{array}$} & \multicolumn{2}{|c|}{ Unadjusted associations } & \multicolumn{2}{|c|}{$\begin{array}{l}\text { Model 1: Demographic and } \\
\text { healthcare utilization variables }\end{array}$} & \multicolumn{2}{|c|}{$\begin{array}{l}\text { Model 2: Model } 1+\text { chronic } \\
\text { conditions }\end{array}$} \\
\hline & $\begin{array}{l}\text { Unadjusted hazard } \\
\text { ratio }\end{array}$ & $95 \% \mathrm{Cl}$ & $\begin{array}{l}\text { Adjusted hazard } \\
\text { ratio }\end{array}$ & $95 \% \mathrm{Cl}$ & $\begin{array}{l}\text { Adjusted hazard } \\
\text { ratio }\end{array}$ & $95 \% \mathrm{Cl}$ \\
\hline & $(N=17,912)$ & & $(n=17,911)$ & & $(n=17,911)$ & \\
\hline Coagulopathy & 1.25 & $0.79-1.98$ & - & - & 0.95 & $0.58-1.54$ \\
\hline Fluid and electrolyte disorders & 1.30 & $0.87-1.95$ & - & - & 1.11 & $0.73-1.68$ \\
\hline Depression & 0.97 & $0.69-1.35$ & - & - & 1.04 & $0.73-1.48$ \\
\hline Liver disease & 1.81 & $1.02-3.20$ & - & - & 1.54 & $0.86-2.75$ \\
\hline
\end{tabular}

Overall follow-up time in days: 1,575,994; average follow-up time in days: $88 .{ }^{a}$ comorbidities defined with coding algorithms for defining Elixhauser comorbidities in ICD-9 administrative data (Quan et al. 2005), $\geq 2$ ICD-9 codes per category, hypertension categories merged, diabetes categories merged, different cancer categories merged, drug abuse, alcohol abuse, obesity, weight loss, HIV/AIDS, paralysis, other neurological disorders, blood loss anemia and deficiency anemia not included, ${ }^{b}$ 90th percentile $=1,{ }^{c} 75$ th percentile $=1{ }^{d}$ categories based on quartiles, ${ }^{\mathrm{e}} 85$ th percentile $=1$

${ }^{* *} p<0.05 ;{ }^{* * *} p<0.001$

Contrasted with patient demographic and health services use factors, the presence of specific chronic comorbidities was generally not found to be associated with new PIM prescribing. This is in line with previous research [22].

Overall, we observed that patients who were newly prescribed a PIM during the follow-up period were slightly sicker, had a higher health services use, and thus were more complex. This increased clinical complexity could lead to less oversight by individual providers on patients' medication regimens, which in turn could make the prevention and reduction of PIM prescribing more difficult. We hypothesize that rather being a question of the individual factors associated with new PIM prescribing, the complexity of individual patients their treatment schedules and medication regimens could be strongly associated with greater PIM prescribing.

These findings have several implications for clinical care. Healthcare professionals, such as pharmacists and physicians, should be aware of key demographic factors that appear to be associated with PIM prescribing when taking prescribing decisions and potentially incorporate these into decision support for prescribers. Relatedly, improvement of care coordination across providers and fragmentation of healthcare prescribing decisions may also be critical ingredients for reducing PIM prescribing in this population, given that more ambulatory visits and unique prescribing orders are also associated with receiving PIMs.

Further, these findings have implications for the design of interventions aimed at reducing the prescribing of PIMs and deprescribing interventions. Prior medication optimization interventions in older adults more broadly have had little or no effect on clinical outcomes, such as mortality or cognitive impairment [55]. Current evidence on interventions in multimorbid older adults using multiple medications remains scarce [56]. Interventions designed to optimize prescribing also may need to be multifaceted, as they should aim at changing behaviors of different stakeholders (e.g. patients, physicians, pharmacists, etc.) and should involve different components (i.e. medication review, education/training, and use different tools/instruments) [57, 58]. Such interventions must not only solve medication-related problems (e.g. PIM prescribing), but they must target the underlying mechanisms that lead to these problems (e.g. complexity). Consequently, while not all of the above-mentioned factors are modifiable, the knowledge of their association with PIM prescribing must be built into medication optimization interventions and may be even more important for this more complex population.

\section{Limitations}

While to the best of our knowledge this study was the first to examine patient factors for new prescribing of PIMs in older multimorbid adults with polypharmacy, there are several limitations. First, the data are from several years ago (owing, in part, to an administrative lag in Medicare data and linking with EHR data); however, prescribing rates of PIMs have not changed since 20072014 [59]. Consequently, we expect the exploration of risk factors to remain highly relevant. Second, due to the criterion-based rather than judgment-based nature of the Beers list, medications indicated in certain circumstances (e.g. use as last resort, etc.) may have been flagged as potentially inappropriate. Despite this, the Beers criteria are the most commonly used tool for defining PIM use in the US and restricting the analyses to medications with medium and high level of evidence did not change the results. Despite our data covering the period from 2007 to 2014, we used the 2019 Beers list to inform current medical decision making. This comes with a modest limitation that medications that were included in the Beers list were excluded in the meantime and some new ones were added. Overall, however, these 
changes only concerned a small number of medications listed in Table 2 of the Beers criteria (e.g., in the 2015 version of the Beers criteria, four medications were removed and three were added; in the 2019 version of the Beers criteria, two medications were removed and three medications were added) [38, 39]. Furthermore, we were not able to adjust our models for the number and types of prescribers, but we specifically focused on patient factors for this reason. Third, we had limited information on dose and route of administration of medications, which may have affected the definition of PIMs; however, this might have led to an underestimation of the prescribing of gastrointestinal PIMs. We also may have underestimated the new prescribing of PIMs because we may not have captured over-the-counter prescribing of medications (e.g. anti-histamines). Fourth, despite the demographic makeup of the Boston metropolitan area being similar to other urban US regions [60], access to healthcare and physicians may be higher in this area compared to other parts of the country. The present study is an observational study, so residual confounding cannot be excluded because of unmeasured or inadequately measured confounders. Finally, there may have been selection bias, since the patients who achieve a high age without being prescribed or using a PIM may differ from those with PIM prescribing or use.

\section{Conclusion}

Several demographic and clinical characteristics are associated with the new prescribing of potentially inappropriate medications in older patients who were naïve to PIMs (e.g. age of $\geq 85$ years, male sex, and number of ambulatory visits). This also indicates that patients with more complex health problems may be at a higher risk of new PIM prescribing. Central nervous system drugs, cardiovascular drugs, anticholinergics and endocrine drugs were the most commonly prescribed PIMs during the 90-day follow-up period. Due to the potential negative outcomes associated with the use of PIMs, these study findings should inform the creation of interventions to improve coordination of care and reduce the prescribing of potentially inappropriate medications in older multimorbid adults with polypharmacy.

\section{Supplementary Information}

The online version contains supplementary material available at https://doi. org/10.1186/s12877-021-02089-x.

\section{Additional file 1.}

\section{Abbreviations}

AGS: American Geriatrics Society; AHRQ: Agency for Healthcare Research and Quality; CCl: Chronic Condition Indicator; CMS: Centers for Medicare and Medicaid Services; EHR: Electronic health records; FDA: Food and Drug Administration; PIMs: Potentially inappropriate medications; RPDR: Partners
Research Patient Data Registry; STROBE: Strengthening the Reporting of Observational Studies in Epidemiology

\section{Acknowledgements}

We thank Professor Albert Hofman for his support.

\section{Authors' contributions}

K.T.J. and J.C.L. conceptualized and designed the study. K.T.J. had full access to all of the data in the study. K.T.J. and J.C.L. analyzed the data. All authors worked on the interpretation of the data and take responsibility for the integrity of the data and the accuracy of the data analysis. All authors critically revised the manuscript. J.C.L. and S.S. provided administrative, technical and material support. J.C.L. supervised the project. The authors read and approved the final manuscript.

\section{Funding}

The work of Katharina Tabea Jungo was supported by the Swiss National Science Foundation (SNSF) through a mobility grant in the OPTICA trial (NFP74 407440_167465, Principal Investigator: Prof Sven Streit).

\section{Availability of data and materials}

The data that support the findings of this study are available from the Research Data Assistance Center (ResDAC) from the Centers for Medicare and Medicaid Services and from Mass General Brigham (formerly Partners Healthcare). Restrictions apply to the availability of these data, which were used under license for the current study, and so are not publicly available. Data may however be available from the authors upon reasonable request and with permission of ResDAC

\section{Ethics approval and consent to participate}

This study was approved by the Brigham and Women's Hospital Institutional Review Board. This analysis is a secondary analysis of subjects in the CMSRPDR dataset. Given the nature of the data previously being collected for routine care, patient consent was waived by the Brigham and Women's Hospital Institutional Review Board. All methods were performed in accordance with the relevant guidelines and regulations (e.g. declaration of Helsinki).

Consent for publication

Not applicable.

\section{Competing interests}

The authors have no conflicts of interests to disclose.

\section{Author details}

${ }^{1}$ Institute of Primary Health Care (BIHAM), University of Bern, Bern, Switzerland. ${ }^{2}$ Department of Epidemiology, Harvard T.H. Chan School of Public Health, Boston, MA, USA. ${ }^{3}$ Division of Pharmacoepidemiology and Pharmacoeconomics, Department of Medicine, Brigham and Women's Hospital and Harvard Medical School, Boston, MA, USA. ${ }^{4}$ Graduate School for Health Sciences, University of Bern, Bern, Switzerland. ${ }^{5}$ Center for Healthcare Delivery Sciences, Department of Medicine, Brigham and Women's Hospital, Boston, MA, USA.

Received: 8 December 2020 Accepted: 15 February 2021

Published online: 06 March 2021

References

1. World Health Organization. Global Health and Ageing. 2011.

2. Johnston MC, Crilly M, Black C, Prescott GJ, Mercer SW. Defining and measuring multimorbidity: a systematic review of systematic reviews. Eur J Pub Health. 2019;29(1):182-9.

3. The Lancet. Making more of multimorbidity: an emerging priority. Lancet. 2018:391(10131):1637.

4. Sakib MN, Shooshtari S, St John P, Menec V. The prevalence of multimorbidity and associations with lifestyle factors among middle-aged Canadians: an analysis of Canadian longitudinal study on aging data. BMC Public Health. 2019;19(1):243.

5. Pearson-Stuttard J, Ezzati M, Gregg EW. Multimorbidity; a defining challenge for health systems. Lancet Public Health. 2019;4(12):e599-600.

6. Moffat K, Mercer SW. Challenges of managing people with multimorbidity in today's healthcare systems. BMC Fam Pract. 2015;16:129. 
7. Salive ME. Multimorbidity in older adults. Epidemiol Rev. 2013;35:75-83.

8. Marengoni A, Angleman S, Melis R, Mangialasche F, Karp A, Garmen A, et al, Aging with multimorbidity: a systematic review of the literature. Ageing Res Rev. 2011;10(4):430-9.

9. Masnoon N, Shakib S, Kalisch-Ellett L, Caughey GE. What is polypharmacy? A systematic review of definitions. BMC Geriatr. 2017;17:230.

10. Kantor ED, Rehm CD, Haas JS, Chan AT, Giovannucci EL. Trends in prescription drug use among adults in the United States from 1999-2012. Jama. 2015;314(17):1818-31.

11. Fu AZ, Liu GG, Christensen DB. Inappropriate medication use and health outcomes in the elderly. J Am Geriatr Soc. 2004;52(11):1934-9.

12. Xing XX, Zhu C, Liang HY, Wang K, Chu YQ, Zhao LB, et al. Associations between potentially inappropriate medications and adverse health outcomes in the elderly: a systematic review and meta-analysis. Ann Pharmacother. 2019;53(10):1005-19.

13. Masumoto S, Sato M, Maeno T, Ichinohe Y, Maeno T. Potentially inappropriate medications with polypharmacy increase the risk of falls in older Japanese patients: 1-year prospective cohort study. Geriatr Gerontol Int. 2018;18(7):1064-70

14. Koyama A, Steinman M, Ensrud K, Hillier TA, Yaffe K. Long-term cognitive and functional effects of potentially inappropriate medications in older women. J Gerontol A Biol Sci Med Sci. 2014;69(4):423-9.

15. Liew TM, Lee CS, Goh Shawn KL, Chang ZY. Potentially inappropriate prescribing among older persons: a meta-analysis of observational studies. Annals Family Med. 2019;17(3):257-66.

16. Hyttinen $\mathrm{V}$, Jyrkka J, Valtonen $\mathrm{H}$. A systematic review of the impact of potentially inappropriate medication on health care utilization and costs among older adults. Med Care. 2016;54(10):950-64.

17. Lau DT, Kasper JD, Potter DE, Lyles A, Bennett RG. Hospitalization and death associated with potentially inappropriate medication prescriptions among elderly nursing home residents. Arch Intern Med. 2005;165(1):68-74.

18. Weeda ER, Al Doughaim M, Criddle S. Association Between Potentially Inappropriate Medications and Hospital Encounters Among Older Adults: A Meta-Analysis. Drugs Aging. 2020;37:529.

19. Heider D, Matschinger $H$, Meid AD, Quinzler R, Adler J-B, Günster C, et al The impact of potentially inappropriate medication on the development of health care costs and its moderation by the number of prescribed substances. Results of a retrospective matched cohort study. Plos One. 2018;13(7):e0198004.

20. Lavan AH, Gallagher PF, O'Mahony D. Methods to reduce prescribing errors in elderly patients with multimorbidity. Clin Interv Aging. 2016; 11:857-66.

21. Fujie K, Kamei R, Araki R, Hashimoto K. Prescription of potentially inappropriate medications in elderly outpatients: a survey using 2015 Japanese guidelines. Int J Clin Pharm. 2020;42(2):579-87.

22. Howard M, Dolovich L, Kaczorowski J, Sellors C, Sellors J. Prescribing of potentially inappropriate medications to elderly people. Fam Pract. 2004; 21(3):244-7.

23. Swanoski MT, Little MM, St Hill CA, Ware KB, Chapman S, Lutfiyya MN. Potentially inappropriate medication prescribing in U.S. older adults with selected chronic conditions. Consult Pharm. 2017;32(9):525-34.

24. Partners Healthcare. Research Patient Data Registry (RPDR) [Internet]. Boston: 2020 [cited February 9, 2021]. Available from: https://rc.partners.org/about/ who-we-are-risc/research-patient-data-registry.

25. Aetion Evidence Platform ${ }^{\circledR}$ (2020). Software for real-world data analysis, which is validated for a range of studies.* Aetion, Inc. http://www.a etion.com.

26. Desai RJ, Lin KJ, Patorno E, Barberio J, Lee M, Levin R, et al. Development and preliminary validation of a Medicare claims-based model to predict left ventricular ejection fraction class in patients with heart failure. Circ Cardiovasc Qual Outcomes. 2018;11(12):e004700.

27. Jungo KT, Streit S, Lauffenburger JC. Utilization and spending on potentially inappropriate medications by US older adults with multiple chronic conditions using multiple medications. Arch Gerontol Geriat. 2021;93.

28. Agency for Healthcare Research and Quality. HCUP Chronic condition Indicator (CCI) [Internet]. Rockville: 2009 [cited February 9, 2021]. Available from: http://www.hcup-us.ahrq.gov/toolssoftware/chronic/chronic.jsp.

29. Franklin JM, Glynn RJ, Martin D, Schneeweiss S. Evaluating the use of nonrandomized real-world data analyses for regulatory decision making. Clin Pharmacol Ther. 2019;105(4):867-77.
30. Smith SM, Wallace E, O'Dowd T, Fortin M. Interventions for improving outcomes in patients with multimorbidity in primary care and community settings. Cochrane Database Syst Rev. 2016;3:Cd006560.

31. Barnett K, Mercer SW, Norbury M, Watt G, Wyke S, Guthrie B. Epidemiology of multimorbidity and implications for health care, research, and medical education: a cross-sectional study. Lancet. 2012;380(9836):37-43.

32. U.S. Food and Drug Administration. National Drug Code Directory 2019 [Available from: https://www.fda.gov/drugs/drug-approvals-and-databases/ national-drug-code-directory].

33. Lauffenburger JC, Franklin JM, Krumme AA, Shrank WH, Matlin OS, Spettell CM, et al. Predicting adherence to chronic disease medications in patients with long-term initial medication fills using indicators of clinical events and health Behaviors. J Managed Care Specialty Pharm. 2018;24(5):469-77.

34. Veehof L, Stewart R, Haaijer-Ruskamp F, Jong BM. The development of polypharmacy. A longitudinal study. Fam Pract. 2000;17(3):261-7.

35. Nishtala PS, Salahudeen MS. Temporal trends in Polypharmacy and Hyperpolypharmacy in older new Zealanders over a 9-year period: 20052013. Gerontology. 2015;61(3):195-202.

36. Wang SV, Verpillat P, Rassen JA, Patrick A, Garry EM, Bartels DB. Transparency and reproducibility of observational cohort studies using large Healthcare databases. Clin Pharmacol Ther. 2016;99(3):325-32.

37. Lin KJ, Rosenthal GE, Murphy SN, Mandl KD, Jin Y, Glynn RJ, et al. External validation of an algorithm to identify patients with high data-completeness in electronic health Records for Comparative Effectiveness Research. Clin Epidemiol. 2020;12:133-41.

38. American Geriatrics Society 2015 Updated Beers Criteria for Potentially Inappropriate Medication Use in Older Adults. J Am Geriatr Soc. 2015;63(11): 2227-46.

39. American Geriatrics Society 2019 Updated AGS Beers Criteria ${ }^{\circledR}$ for Potentially Inappropriate Medication Use in Older Adults. J Am Geriatr Soc. 2019;67(4): 674-94.

40. American Geriatrics Society updated Beers Criteria for potentially inappropriate medication use in older adults. J Am Geriatr Soc. 2012;60(4): 616-31

41. Tommelein E, Mehuys E, Petrovic M, Somers A, Colin P, Boussery K. Potentially inappropriate prescribing in community-dwelling older people across Europe: a systematic literature review. Eur J Clin Pharmacol. 2015. 71(12):1415-27.

42. Nothelle SK, Sharma R, Oakes A, Jackson M, Segal JB. Factors associated with potentially inappropriate medication use in community-dwelling older adults in the United States: a systematic review. Int J Pharm Pract. 2019; 27(5):408-23.

43. Quan H, Sundararajan V, Halfon P, Fong A, Burnand B, Luthi JC, et al. Coding algorithms for defining comorbidities in ICD-9-CM and ICD-10 administrative data. Med Care. 2005;43(11):1130-9.

44. Kim DH, Schneeweiss S, Glynn RJ, Lipsitz LA, Rockwood K, Avorn J. Measuring frailty in Medicare data: development and validation of a claimsbased frailty index. J Gerontol A Biol Sci Med Sci. 2018;73(7):980-7.

45. Sullivan GM, Feinn R. Using effect size-or why the P value is not enough. J Graduate Med Educ. 2012;4(3):279-82.

46. von Elm E, Altman DG, Egger M, Pocock SJ, Gøtzsche PC, Vandenbroucke $J P$. The strengthening the reporting of observational studies in epidemiology (STROBE) statement: guidelines for reporting observational studies. J Clin Epidemiol. 2008;61(4):344-9.

47. Bony H, Lloyd RA, Hotham ED, Corre LJ, Corlis ME, Loffler HA, et al. Differences in the prescribing of potentially inappropriate medicines in older Australians: comparison of community dwelling and residential aged care residents. Sci Rep. 2020;10(1):10170.

48. Faustino CG, Passarelli MC, Jacob-Filho W. Potentially inappropriate medications among elderly Brazilian outpatients. Sao Paulo medical journal =. Rev Paul Med. 2013;131(1):19-26.

49. Al-Azayzih A, Alamoori R, Altawalbeh SM. Potentially inappropriate medications prescribing according to beers criteria among elderly outpatients in Jordan: a cross sectional study. Pharm Pract. 2019;17(2):1439.

50. Bhatt AN, Paul SS, Krishnamoorthy S, Baby BT, Mathew A, Nair BR. Potentially inappropriate medications prescribed for older persons: a study from two teaching hospitals in southern India. J Fam Community Med. 2019;26(3): 187-92.

51. Goulding MR. Inappropriate medication prescribing for elderly ambulatory care patients. Arch Intern Med. 2004;164(3):305-12. 
52. Buck MD, Atreja A, Brunker CP, Jain A, Suh TT, Palmer RM, et al. Potentially inappropriate medication prescribing in outpatient practices: prevalence and patient characteristics based on electronic health records. Am J Geriatr Pharmacother. 2009; (2):84-92.

53. Extavour RM, Perri M 3rd. Patient, physician, and health-system factors influencing the quality of antidepressant and sedative prescribing for older, community-dwelling adults. Health Serv Res. 2018;53(1):405-29.

54. Clark CM, Shaver AL, Aurelio LA, Feuerstein S, Wahler RG Jr, Daly CJ, et al. Potentially Inappropriate Medications Are Associated with Increased Healthcare Utilization and Costs. J Am Geriatr Soc. 2020;68:2542.

55. Huiskes VJB, Burger DM, van den Ende CHM, van den Bemt BJF. Effectiveness of medication review: a systematic review and meta-analysis of randomized controlled trials. BMC Fam Pract. 2017;18(1):5.

56. Rankin A, Cadogan CA, Patterson SM, Kerse N, Cardwell CR, Bradley MC, et al. Interventions to improve the appropriate use of polypharmacy for older people. Cochrane Database Syst Rev. 2018;9:Cd008165.

57. Lee JQ, Ying K, Lun P, Tan KT, Ang W, Munro Y, et al. Intervention elements to reduce inappropriate prescribing for older adults with multimorbidity receiving outpatient care: a scoping review. BMJ Open. 2020;10(8):e039543.

58. Santos NSD, Marengo LL, Moraes FDS, Barberato FS. Interventions to reduce the prescription of inappropriate medicines in older patients. Revista de saude publica. 2019:53:7.

59. Fralick M, Bartsch E, Ritchie CS, Sacks CA. Estimating the Use of Potentially Inappropriate Medications Among Older Adults in the United States. J Am Geriatr Soc. 2020;68:2927.

60. Kaiser Family Foundation (KFF). Profile of Medicare Beneficiaries by Race and Ethnicity: A Chartpack. 2020 [Available from: https://www.kff.org/reportsection/profile-of-medicare-beneficiaries-by-race-and-ethnicity-chartpack/].

\section{Publisher's Note}

Springer Nature remains neutral with regard to jurisdictional claims in published maps and institutional affiliations.

Ready to submit your research? Choose BMC and benefit from:

- fast, convenient online submission

- thorough peer review by experienced researchers in your field

- rapid publication on acceptance

- support for research data, including large and complex data types

- gold Open Access which fosters wider collaboration and increased citations

- maximum visibility for your research: over $100 \mathrm{M}$ website views per year

At BMC, research is always in progress.

Learn more biomedcentral.com/submissions 